\title{
Urbanização, Favelas e Endemias: A Produção da Filariose no Recife, Brasil
}

\author{
Urbanization, Slums, and Endemics: The Production of Filariasis in \\ Recife, Brazil
}

\author{
Maria de Fátima P. M. Albuquerque ${ }^{1}$
}

\begin{abstract}
ALBUQUERQUE, M. F. P. M. Urbanization, Slums, and Endemics: The Production of Filariasis in Recife, Brazil. Cad. Saúde Públ., Rio de Janeiro, 9 (4): 487-497, Oct/Dec, 1993. In this article the filariasis endemic is discussed as a public health problem in the city of Recife, capital of the state of Pernambuco, Brazil. Prevalence figures for this parasitic disease in some urban settings are cause for concern. The urban development process, characterized by disordered growth of cities and an increase in the number of slums, is pointed out as an important factor for the maintenance of conditions favouring disease transmission. Some analytical categories linked to urban social organization are identified and included in a comprehensive filariasis transmission model. Clusters of inadequate houses built in overcrowded slums without basic sanitation or a proper drainage system produce adequate conditions for proliferation of infection vectors and maintenance of the endemic.
\end{abstract}

Key words: Filariasis; Endemics; Urbanization and Diseases; Recife; Brazil

\section{INTRODUÇÃO}

A filariose linfática é uma infecção causada pelos parasitas nematódeos Wuchereria bancrofti, Brugia malayi e Brugia timori, sendo endêmica principalmente em países da Ásia e África. Focos localizados da infecção são encontrados também na América do Sul, América Central, algumas ilhas do Caribe e grande parte das ilhas do Pacífico (OMS, 1988).

A Organização Mundial da Saúde estima a existência de cerca de 751 milhões de pessoas vivendo em áreas endêmicas. Destas, 72,8 milhões estão infectadas com $W$. bancrofti e 5,8 milhões com B. malayi ou B. timori (WHO, 1992).

No Brasil, a cidade do Recife, no Estado de Pernambuco, e a cidade de Belém, no Estado do Pará, permanecem como focos da endemia desde os primeiros inquéritos de prevalência, realizados há cerca de 40 anos atrás (Rachou,

\footnotetext{
${ }^{1}$ Núcleo de Estudos em Saúde Coletiva, Centro de Pesquisas Aggeu Magalhães. Rua dos Coelhos 450 (antigo Hospital D. Pedro II), Recife, PE, 50070-550, Brasil.
}

1957), sendo que em Belém a endemia é considerada sob controle (Dreyer \& Medeiros, 1990).

Na cidade do Recife, a filariose, apesar de, há alguns anos atrás, parecer uma endemia de fácil controle (MS, 1983, 1985), apresenta hoje níveis de prevalência de microfilaremia (presença de microfilárias no sangue de indivíduos infectados) de até $15 \%$ em algumas de suas áreas urbanas (WHO, 1992). A permanência desta parasitose como um problema de saúde pública no Recife, à semelhança do que vem ocorrendo com outras endemias prevalentes em áreas urbanas e periurbanas dos países em desenvolvimento, parece estar relacionada ao processo de urbanização (Silva, 1985; Mott et al., 1990).

O desenvolvimento urbano é um processo complexo que envolve fenômenos sociais e econômicos, tais como migração da área rural para a cidade, oportunidades de trabalho e infra-estrutura de serviços urbanos, e, como tal, tem um impacto na saúde da população (Mott et al., 1990). Este impacto se faz sentir com mais intensidade nos países em desenvolvimento, como expressão das desigualdades sócioespaciais no interior dos espaços urbanos. 
Nessas cidades, a urbanização tem-se caracterizado pela criação do que Santos (1979) denominou "os dois circuitos da economia urbana": de um lado, a modernização tecnológica, com atividades criadas em função da mesma e dirigidas às pessoas que se beneficiam dela; do outro, o chamado "circuito inferior", caracterizado pela multiplicidade de atividades do setor terciário e pela pequena produção manufatureira.

As diferenças marcantes entre estes dois circuitos urbanos dos países subdesenvolvidos expressam-se, também, no acesso a habitações adequadas e nos perfis de morbi-mortalidade. Este é o caso da maioria das cidades brasileiras, principalmente as grandes áreas metropolitanas. Produto de movimentos migratórios intensificados entre as décadas de 50 e 70 (Durham, 1984) e de conflitos sociais que vêm determinando sua expansão desordenada, essas áreas urbanas tornaram-se palco de um quadro sanitário complexo (Sabroza et al., 1992).

É justamente com a intenção de evidenciar a relação existente entre os processos que compõem a organização social de um dado espaço geográfico e a produção de doenças ao nível coletivo que vem sendo proposto um novo conceito de endemia. Este não se aplica apenas a algumas doenças de massas, cuja ocorrência procura-se explicar através de fatores climáti$\cos$.

O conceito de endemia deve, de forma mais abrangente, ser entendido como " $a$ expressão no nível coletivo do processo saúde enfermidade, produto de um conjunto estruturado de processos determinantes de uma doença, em unidades particulares de uma formação econômicosocial" (Sabroza, 1991).

O estudo da distribuição das endemias, ou seja, a explicação das variações no perfil de saúde e doença ao nível do coletivo, deve abranger, portanto, os processos de reprodução social das condições de existência de grupos populacionais. Estes processos particulares de uma formação econômico-social representam as categorias de mediação entre a sociedade e os fenômenos concretos de saúde e enfermidade (Castellanos, 1990).

No caso da filariose bancroftiana endêmica, cabe questionar quais as "categorias mediadoras", representantes da organização social do espaço urbano, que devem ser incluídas em um modelo compreensivo da sua transmissão e, ainda, quais as especificidades deste modelo na cidade do Recife.

Neste sentido, procuraremos contribuir para uma melhor compreensão acerca da ocorrência de filariose endêmica no Recife, identificando os aspectos de maior relevância do processo de urbanização desta cidade nas últimas décadas, os quais terminam por determinar precárias condições de vida para certos segmentos populacionais, estabelecendo a mediação com o ciclo infeccioso básico da parasitose.

\section{CARACTERÍSTICAS DA TRANSMISSÃO DA W. bancrofti}

No Recife, a filariose linfática tem como único agente etiológico a W. bancrofti, transmitida pelo Culex quinquefasciatus, um mosquito hematófago no qual se processa, obrigatoriamente, um dos estágios de maturação do parasita.

O ciclo evolutivo dos vermes filariais tem início no homem, seu único hospedeiro definitivo, com a picada do vetor portador de larvas infectantes.

Essas larvas não se multiplicam no vetor e, conseqüentemente, o seu número depende da quantidade de microfilárias ingeridas a partir de hospedeiros infectados (OMS, 1988).

Além disso, alguns fatores, como temperatura e umidade da pele, interagem, dificultando a sobrevivência das larvas e o seu caminho até o sistema linfático do homem. Muitos parasitas não conseguem penetrar na pele do hospedeiro, enquanto outros não alcançam os vasos linfáticos. Além disso, muitos dos que os alcançam são "rejeitados" pelas respostas imunes (Nelson, 1979). Todos esses fatores contribuem para uma relativa "ineficiência" da transmissão (Hairston \& Meillon, 1968).

Não existem reservatórios animais da infecção, que só parece ocorrer, em face de todos esses obstáculos, em áreas onde há uma alta densidade de vetores infectados (Nelson, 1979).

Por esta razão, a presença de condições favoráveis à proliferação de criadouros do vetor - água estagnada e poluída nos ambientes domiciliar e peridomiciliar - parece ser uma 
das circunstâncias mediadoras da relação existente entre condições de vida nos espaços urbanos periféricos e a persistência da filariose endêmica.

\section{A ENDEMIA NO RECIFE UMA BREVE RETROSPECTIVA}

A filariose bancroftiana só foi considerada endêmica no Recife, pelo Ministério da Saúde, a partir de 1952, após a realização de um inquérito de prevalência de microfilaremia em um dos bairros da cidade (Azevedo \& Dobbin, 1952).

Em 1956 concluía-se um outro inquérito de abrangência nacional, conduzido pelo Ministério da Saúde e coordenado por René Rachou. A cidade do Recife foi então apontada como um dos dois focos endêmicos de maior importância no país, ao lado de Belém, no Estado do Pará, com uma prevalência de microfilaremia de $6,9 \%$ para a cidade como um todo (Rachou, 1957; Rachou et al., 1956).

A partir de então, foram iniciadas as ações de controle, empreendidas, primeiramente, pelo Departamento Nacional de Endemias Rurais (DNERu) e, depois de 1970, pela Superintendência de Campanhas de Saúde Pública (Sucam).

No Recife, o Programa de Controle da Filariose esteve sempre fundamentado no tratamento seletivo dos indivíduos infectados e em ações esporádicas de combate ao vetor (Azevedo, 1967; Morais, 1982; MS, 1985). A identificação dos indivíduos infectados, microfilarêmicos, vem sendo realizada através da "busca ativa", isto é, de inquéritos hemoscópicos anuais em bairros da cidade, e da demanda espontânea aos postos de saúde ligados ao Programa de Controle, atividade esta denominada "busca passiva".

A partir de 1983, as intervenções de controle passaram a ser realizadas também em Olinda e, a partir de 1989, em outros municípios da área metropolitana do Recife. Isto veio a demonstrar que algumas destas cidades, como, por exemplo, Olinda, Jaboatão e Paulista, são áreas endêmicas de filariose (MS, 1983, 1989).
Os relatórios anteriores das instituições responsáveis pelo Programa de Controle descrevem um declínio da endemia em Pernambuco, tendo o índice de lâminas positivas (ILP) para microfilárias decrescido de 6,9\%, em 1954, para $1,5 \%$, em 1983. Este fato levou à conclusão de que "a endemia vem sendo controlada de forma satisfatória" (MS, 1985).

Um estudo realizado em 1982 já levantava algumas questões em relação a este suposto controle, na medida em que demonstrava que o declínio observado nos índices de microfilaremia, de 1954 até o início da década de 80, não era constatado quando decomposto para os vários distritos da cidade. Além disso, em alguns deles, na realidade, a prevalência havia aumentado ao longo do período (Morais, 1982).

O Centro de Pesquisas Aggeu Magalhães (CPqAM), da Fundação Oswaldo Cruz, com a colaboração da Organização Mundial da Saúde, desde 1986 vem realizando inquéritos de prevalência da infecção, identificando as áreas de maior endemicidade na cidade.

$\mathrm{O}$ resultado destes inquéritos evidenciaram que, em algumas áreas, em geral de favelas, os índices de microfilaremia estão próximos a $15 \%$ (MS, 1990; Dreyer \& Medeiros, 1990; WHO, 1992).

Em relação à evolução dos índices microfilarêmicos para o município do Recife como um todo, na última década, a partir da busca ativa e da demanda aos postos de notificação (busca passiva), observamos um aumento no percentual de positividade a partir de 1988 (Tabelas 1 e 2; Figura 1).

É preciso ressaltar que, em 1990, ano em que o percentual de positividade alcançou $6,2 \%$, só foram efetuadas atividades de busca ativa em 32 bairros, considerados assentamentos populares pela Prefeitura do município. Este inquérito, realizado pelo $\mathrm{CPqAM}$, em convênio com a Sucam e com a Prefeitura da cidade, utilizou procedimentos metodológicos diferentes dos habitualmente empregados pelo Programa de Controle (MS, 1990).

A análise detalhada de seus resultados fornecerá subsídios para a implementação e reorientação das ações de controle da filariose bancroftiana no Recife. 
TABELA 1. Índices Microfilarêmicos do Recife por Busca Ativa, Período 1981 a 1991

\begin{tabular}{lrrr}
\hline \hline Anos & \multicolumn{1}{c}{$\begin{array}{l}\text { Lâminas } \\
\text { Colhidas }\end{array}$} & $\begin{array}{c}\text { Lâminas } \\
\text { Positivas }\end{array}$ & $\begin{array}{c}\% \\
\text { de Positivos }\end{array}$ \\
\hline 1981 & 290.1135 & 4816 & 1,7 \\
1982 & 290.914 & 4549 & 1,6 \\
1983 & 210.711 & 2029 & 1,0 \\
1984 & 205.298 & 1365 & 0,7 \\
1985 & 200.764 & 1268 & 0,6 \\
1986 & 103.969 & 1403 & 1,3 \\
1987 & 76.900 & 661 & 0,9 \\
1988 & 101.992 & 1423 & 1,4 \\
1989 & 95.467 & 20354 & 2,1 \\
$1990^{(*)}$ & 10.881 & 676 & 6,2 \\
1991 & 54.376 & 1880 & 3,5 \\
\hline \hline
\end{tabular}

Fonte: MS/FNS/Diretoria Regional de Pernambuco/Relatórios Estatísticos Mensais da Campanha contra a Filariose (MS, 1989, 1990).

(*) Busca Ativa realizada através de procedimentos metodológicos diferentes dos habitualmente adotados pelo Programa.

TABELA 2. Índices Microfilarêmicos do Recife por Busca Passiva, Período 1981 a 1991

\begin{tabular}{lrrr}
\hline \hline Anos & \multicolumn{2}{c}{$\begin{array}{l}\text { Lâminas } \\
\text { Colhidas }\end{array}$} & \multicolumn{2}{c}{$\begin{array}{c}\text { Lâminas } \\
\text { Positivas }\end{array}$} & $\begin{array}{c}\% \\
\text { de Positivos }\end{array}$ \\
\hline 1981 & 28.359 & 774 & 2,7 \\
1982 & 33.258 & 631 & 1,9 \\
1983 & 36.107 & 448 & 1,2 \\
1984 & 44.142 & 375 & 0,8 \\
1985 & 25.593 & 27 & 0,1 \\
1986 & 48.379 & 688 & 1,4 \\
1987 & 68.601 & 1107 & 1,6 \\
1988 & 53.283 & 582 & 1,1 \\
1989 & 43.850 & 658 & 1,5 \\
1990 & 43.111 & 1371 & 3,2 \\
1991 & 42.542 & 1583 & 3,7 \\
\hline \hline
\end{tabular}

Fonte: MS/FNS/Diretoria Regional de Pernambuco/Relatórios Estatísticos Mensais da Campanha contra a Filariose (MS, 1989, 1990).

\section{A OCUPAÇÃO DO ESPAÇO URBANO DO RECIFE E A FILARIOSE ENDÊMICA}

A cidade do Recife está localizada numa área do delta e do vale inferior do rio Capibaribe, o que condiciona a formação de uma "espécie de cidade arquipélago". A sua expansão urbana ocorreu a partir do seu bairro portuário, transpondo o rio Capibaribe, perto da embocadura, e indo ocupar a ilha onde atualmente situam-sse os bairros de Santo Antônio e São José (Melo, 1978).
Esta situação geográfica tornou escassas as áreas de terra firme até o século XIX, fazendo com que parte da ocupação do continente só viesse a ocorrer posteriormente, através da realização de aterros de áreas alagadas.

A partir de 1940, as mudanças resultantes do processo de industrialização no Estado de Pernambuco estiveram associadas às migrações da área rural para a cidade do Recife, adicionando novos e importantes componentes na formação do espaço urbano.

Com o aparecimento das usinas de açúcar, 
FIGURA 1. Índices Microfilarêmicos do Recife, Período 1981 a 1991

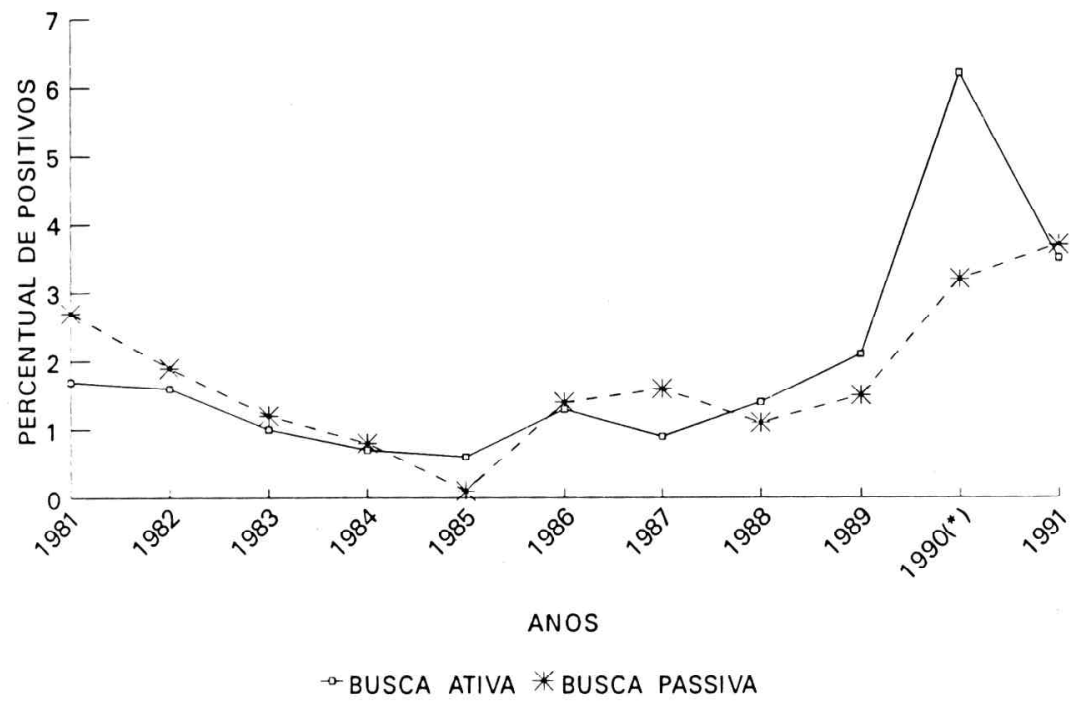

\footnotetext{
${ }^{(*)}$ Busca Ativa realizada através de procedimentos metodológicos diferentes dos habitualmente adotados pelo Programa.
}

mudaram as relações de trabalho agrícola e os trabalhadores deixaram de ter acesso à terra para o plantio da lavoura de subsistência. Além disso, as usinas absorviam um menor número de trabalhadores, que, gradativamente, forma sendo atraídos para a Capital, em busca de emprego e de melhores condições de vida. A este contingente populacional, proveniente da região canavieira, somavam-se outros, vindos de outras regiões do Estado, em decorrência de secas periódicas (Melo, 1978).

A cidade do Recife passou, então, a representar uma área de convergência de movimentos migratórios, intensificados nas décadas de 50 e 70 , os quais estiveram fortemente correlacionados à sua metropolização. Entre 1960 e 1970, a população da Região Metropolitana do Recife cresceu $44,5 \%$, sendo que, neste último ano, $33,5 \%$ do total dessa população eram constituídos de imigrantes (Melo, 1978).

Esses fluxos migratórios vêm se mantendo de forma menos acelerada (Fibge, 1982). Segundo resultados preliminares do Censo Demográfico de 1991, a participação relativa da Região Metropolitana do Recife, em relação ao Estado, passou de 38,2, em 1980, para 40,2 em 1991 (Fibge, 1992a).
Apesar da política de incentivos governamentais à industrialização do Nordeste, o pólo industrial criado no Estado de Pernambuco, mais especificamente na Região Metropolitana do Recife, não foi proporcional ao crescimento demográfico, não sendo o mesmo capaz de absorver a mão-de-obra disponível.

Em decorrência disso, apenas uma parte dos migrantes é absorvida pelo mercado de trabalho, sendo que, a inserção desta mão-de-obra ocorre no setor de comércio e serviços, onde se registram os mais baixos salários (Melo, 1978). A grande maioria desempregada ou subempregada termina por se fixar em favelas e áreas de invasão, fornecendo-nos um exemplo concreto de como a desigualdade social determina acessos distintos a espaços urbanos capazes de suprir as necessidades da população (Santos, 1979).

É neste contexto que devemos entender a filariose endêmica no Recife, uma cidade cujo crescimento ocorreu a despeito do seu "despreparo" para atender ao ritmo e à quantidade das demandas criadas.

Nesses últimos 40 anos, desde a realização dos primeiros inquéritos de prevalência de microfilaremia até os dias de hoje, a qualidade 
de vida de uma parcela significativa da população do Recife vem gradativamente se deteriorando.

Em relação às políticas públicas de habitação, estas aparecem, como no restante do país, como altamente seletivas, na medida em que, permitindo que prevaleça a lógica de mercado, impossibilitam que os segmentos pobres da população tenham acesso à moradia em locais adequados (Melo, 1990).

É possível verificar que mesmo as ações de governo voltadas para o atendimento específico da população de baixa renda não respondem necessariamente aos interesses desses segmentos. Como exemplo, podemos citar o PROMORAR. Criado com o objetivo de propiciar a fixação dos moradores das favelas, através da urbanização destas áreas, este programa terminou por se constituir, na avaliação de Melo (1991), em uma estratégia eleitoral.

Com o agravamento da crise econômica no país e impossibilitada de garantir sua sobrevi- vência, seja pelo desemprego ou pelo subemprego, uma parcela considerável da população recifense busca solucionar o seu problema de moradia através da invasão coletiva de áreas urbanas. No período compreendido entre 1979 e 1984 ocorreram cerca de 201 invasões de terra na Região Metropolitana do Recife (Moura, 1990).

Existem hoje 223 favelas no município do Recife, sendo que nestas encontram-se 42,2\% dos domicílios construídos na cidade. Este percentual do município de domicílios construídos em favelas revela-se excessivamente alto quando comparado com aqueles dos municípios-sede das nove regiões metropolitanas do país (Fibge, 1992b) (Tabela 3, Figura 2).

É importante salientar que a densidade demográfica média destes assentamentos populares, no Recife, é de 251,01 hab./ha (PCR, 1991), enquanto a densidade demográfica da cidade do Recife como um todo é de 58,9 hab./ha (Fibge, 1992b).

TA BELA 3. Número de Favelas e Estimativas dos Domicílios segundo os Municípios Sede das Nove Regiões Metropolitanas do Brasil

\begin{tabular}{lcccc}
\hline \hline \multirow{2}{*}{$\begin{array}{l}\text { Municípios Sede } \\
\text { das Nove Regiões } \\
\text { Metropolitanas do Brasil }\end{array}$} & $\begin{array}{l}\text { Número } \\
\text { de Favelas }\end{array}$ & $\begin{array}{c}\text { Nos } \\
\text { Municípios }\end{array}$ & $\begin{array}{c}\text { Nas } \\
\text { Favelas }\end{array}$ & $\begin{array}{c}\% \\
\text { em Relação } \\
\text { ao Município }\end{array}$ \\
\cline { 3 - 5 } Belém (PA) & 20 & 256.782 & 38.831 & 15,1 \\
\hline Fortaleza (CE) & 115 & 383.680 & 51.361 & 13,3 \\
\hline Recife (PE) & 223 & 310.820 & 131.325 & 42,2 \\
\hline Salvador (BA) & 62 & 470.085 & 17.595 & 3,7 \\
\hline Belo Horizonte (MG) & 103 & 517.146 & 51.735 & 10,0 \\
\hline Rio de Janeiro (RJ) & 394 & 1.627 .366 & 203.226 & 12,4 \\
\hline São Paulo (SP) & 594 & 2.649 .836 & 134.448 & 5,0 \\
\hline Curitiba (PA) & 87 & 328.042 & 22.021 & 6,7 \\
\hline Porto Alegre (RGS) & 69 & 386.499 & 25.371 & 6,5 \\
\hline \hline
\end{tabular}

Fonte: FIBGE, 1992b. 
FIGURA 2. Mapa dos Assentamentos Populares do Recife, 1991

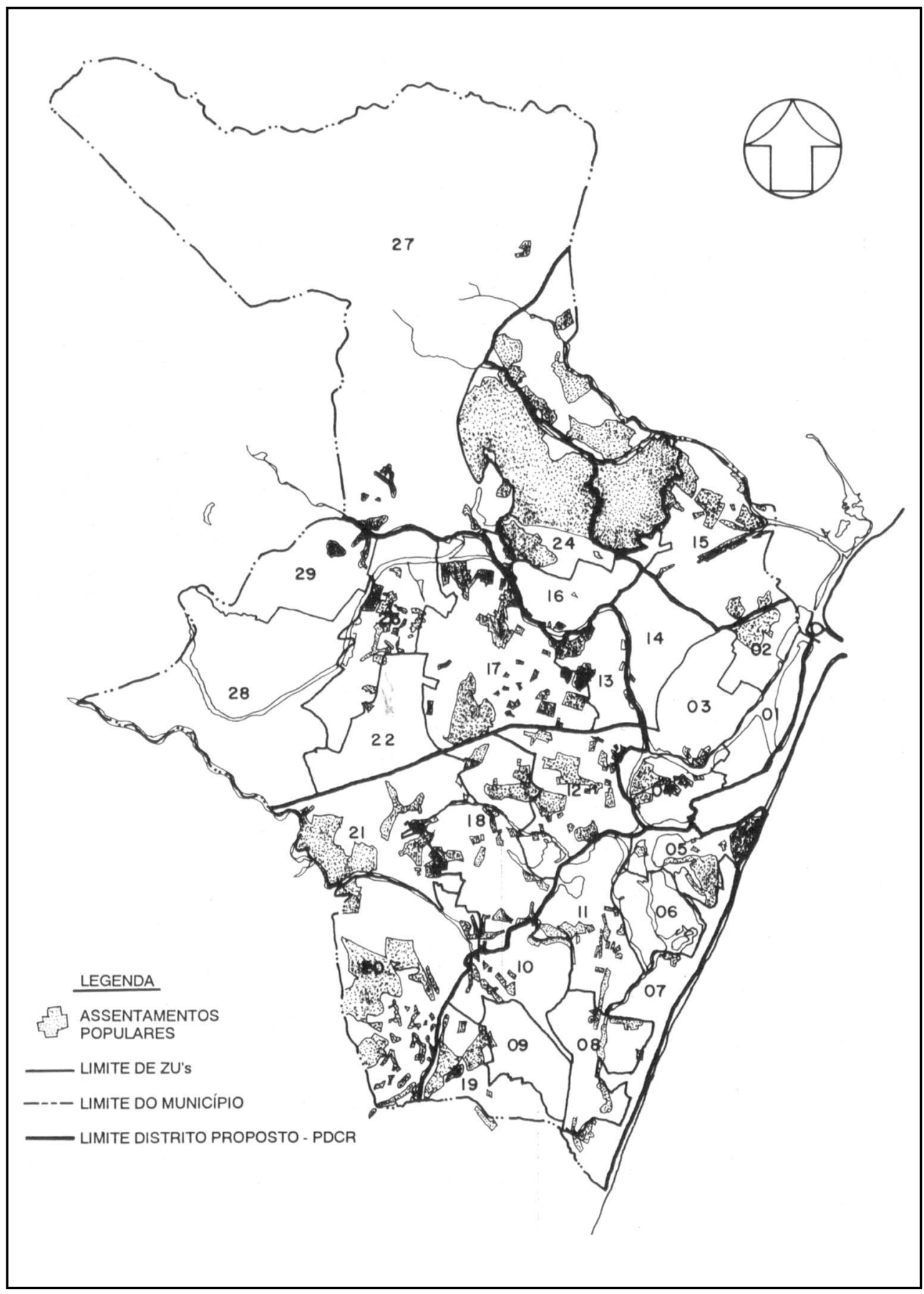

Fonte: Plano Diretor de Desenvolvimento da Cidade do Recife, PCR/SPL.

Consórcio PROCENGE/URBANA/ACQUAPLAN (PCR, 1991). 
Em uma cidade onde o sistema público de esgotos sanitários atende precariamente pouco mais de $30 \%$ da população (PCR, 1991), é justamente nas áreas de favelas onde a deficiência deste e de outros serviços de infra-estrutura urbana se faz sentir com mais intensidade.

Não nos surpreendem, portanto, os resultados encontrados por Rocha \& Villela (1990), que situam a cidade do Recife entre as três regiões metropolitanas brasileiras, ao lado de Fortaleza e Belém, que apresentam populações pobres com os mais baixos níveis de qualidade de vida.

Para os autores, isto significa que "as condições de vida dos quase $60 \%$ de pessoas pobres, que compõem as subpopulações como definidas em 1983 para Fortaleza, Recife e Belém, são em muito inferiores às da subpopulação pobre que representam cerca de $30 \%$ da população total em Porto Alegre, por exemplo" (Rocha \& Villela, 1990).

Desta forma, fica claro como a filariose endêmica acaba por se constituir em mais um indicador de pobreza no Recife.

Os aglomerados de casas malconstruídas nas favelas, em áreas alagadas, sem serviços de saneamento e cercadas de fossas abertas, oferecem as condições adequadas para criadouros do C. quinquefasciatus. Em janeiro de 1991, por exemplo, registrou-se, em uma noite, uma média de 127,3 mosquitos C. quinquefasciatus por casa em uma das favelas da cidade (CPqAM, 1992).

\section{CONSIDERAÇÕES FINAIS}

A construção de modelos explicativos que contemplem a complexidade e a hierarquização dos diferentes níveis de determinação das doenças vem sendo proposta por alguns autores já há algum tempo (Barbosa, 1984; Dias \& Dias, 1979; Castellanos, 1990). Estes modelos incluem categorias de análise e variáveis que representam processos sociais, formas e acumulações anteriores, ligados entre si por uma organização. Esta organização se definir-se-ia como um conjunto de regras e leis que regem as relações de cada variável com as demais (Castellanos, 1990).

Em relação à filariose, sem dúvida, algumas questões a respeito do seu ciclo infeccioso básico precisam ainda ser esclarecidas. Porém, o entendimento dos parâmetros necessários à manutenção deste ciclo requer uma visão global e integrada dos fatores estruturais envolvidos.

Desta forma, é necessário incluir no modelo de explicação da filariose endêmica categorias de análise e variáveis que representem a organização social do espaço onde ela ocorre.

A Figura 3 apresenta um modelo de determinação da filariose no Recife que inclui categorias de análise e variáveis de diferentes níveis que se articulam para a produção da endemia.

A urbanização da cidade do Recife vem produzindo espaços intra-urbanos extremamente desiguais. Esta diferenciação social do espaço não significa apenas desigualdades nas "formas de morar". Mais abrangente, ela tem um impacto na qualidade de vida e de saúde dos grupos populacionais residentes em áreas insalubres e desprovidas de serviços de infra-estrutura urbana.

Associam-se a esta organização social da cidade os condicionamentos de sua situação geográfica. Cortada por rios e canais e construída, em boa parte, às custas de aterro de áreas de mangue, a cidade do Recife está sujeita a alagamentos periódicos.

Além disso, o vetor da $W$. bancrofti nesta cidade, o $C$. quinquefasciatus, é um mosquito que se prolifera, preferencialmente, em água estagnada e poluída, estando, portanto, associado às condições precárias de saneamento.

É nas áreas de favelas, em geral superpovoadas, onde se acumulam no ambiente domiciliar e peridomiciliar a água usada de origem doméstica. Os terrenos alagados, as valas de drenagem e as fossas abertas produzem as condições adequadas para os criadouros do vetor capaz de manter a transmissão da parasitose.

Portanto, em um modelo compreensivo da filariose endêmica no Recife, a migração, o desemprego e o subemprego, além das políticas 
públicas de saúde, habitação e saneamento, devem ser consideradas categorias mediadoras entre o nível geral e o nível particular de determinação da filariose.

Da mesma forma, a "favelização", ao criar espaços onde coexistem uma alta densidade populacional e condições favoráveis à formação de criadouros do vetor, constitui-se em uma categoria mediadora entre o nível particular e o nível singular, articulando a organização social da cidade ao ciclo infeccioso básico da parasitose.
Este conjunto de categorias e variáveis, bem como as relações entre elas, deve ser considerado em estudos que pretendam analisar as razões da permanência da filariose endêmica no Recife.

\section{AGRADECIMENTOS}

Agradecemos aos Professores Mauro C. de Almeida Marzochi e Paulo C. Sabroza pela orientação e leitura crítica do texto.

FIG URA 2. Modelo Compreensivo da Transmissão da Filariose Bancroftiana Urbana

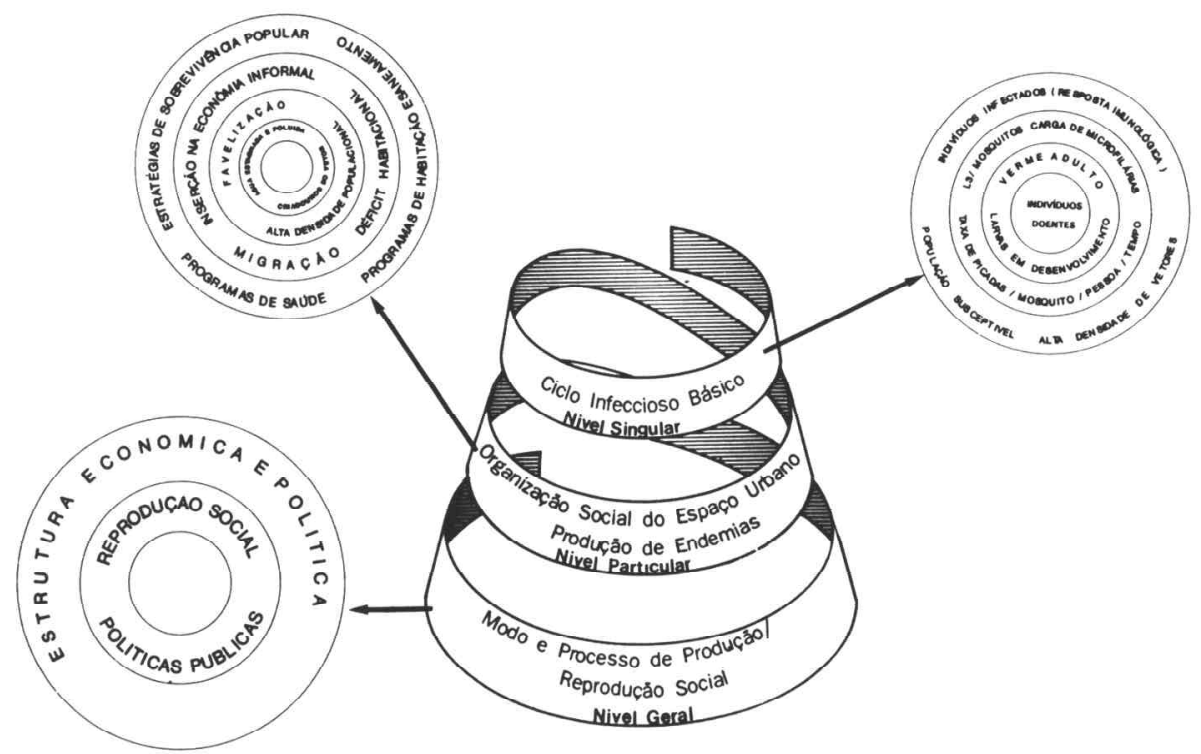

\section{RESUMO}

\section{ALBUQUERQUE, M. F. P. M. Urbanização,} Favelas e Endemias: A Produção da Filariose no Recife, Brasil. Cad. Saúde Públ., Rio de Janeiro, 9 (4): 487-497, out/dez, 1993.

Neste artigo discutimos a ocorrência da filariose como um problema de saúde pública na cidade do Recife, capital do Estado de Pernambuco, que apresenta ainda hoje, em algumas áreas, níveis de prevalência preocupantes. Procura-se mostrar o papel da evolução urbana da cidade, caracterizada por um crescimento desordenado e pela formação de um número crescente de favelas, na criação de condições propícias para a transmissão desta parasitose. Identificamos categorias de análise, ligadas à organização social do espaço urbano, que devem ser incluídas como "mediadoras" em um modelo compreensivo da transmissão da filariose. Os aglomerados de habitações inadequadas, construídas em favelas superpovoadas, sem saneamento básico e sem sistema de 
drenagem de águas, propiciam as condições adequadas à proliferação dos mosquitos vetores da infecção e à manutenção da endemia.

Palavras-Chave: Filariose; Endemias; Urbanização e Doenças, Recife, Brasil

\section{REFERÊNCIAS BIBLIOGRÁFICAS}

AZEVEDO, R. \& DOBBIN, J. E, 1952. Filariose (W. bancrofti) no grupo residencial do IAPB no bairro dos Afogados (Recife). Publicações A vulsas do Instituto A ggeu M agalhães, 1: 157-162.

AZEVEDO, R., 1967. Sete anos de campanha antifilariótica no Recife. A Folha M édica, 54: 75-87.

BARBOSA, F. S., 1984. A Epidemiologia como instrumento de análise. SENECTA, 7: 31-35.

CASTELLANOS, P. L., 1990. Sobre el concepto de salud-enfermedad. Descripción y explicación de la situación de salud. Boletin Epidemiológico (OPS), 10 (4), $7 \mathrm{pp}$.

CPqAM (Centro de Pesquisas Aggeu Magalhães), 1992. Sucesso no controle da filariose. Informe Fiedlincs, Rio de Janeiro, 1: 7.

DIAS, J. C. P. \& DIAS, R. B., 1979. Aspectos sociais, econômicos e culturais da doença de Chagas. Ciência e Cultura, 31 (Supl.): 105-117.

DREYER, G. \& MEDEIROS, Z., 1990. Filariose Linfática: Ainda um desafio. Ciência Hoje, 12: 6-7.

DURHAM, E. R., 1984. A Caminho da Cidade. São Paulo: Editora Perspectiva.

FIBGE (Fundação Instituto Brasileiro de Geografia e Estatística), 1982. IX Recenseamento Geral Brasileiro, 1980 (Pernambuco. Censo Demográfico. Dados Distritais). Vol. 1, Tomo 3, $\mathrm{n}^{\circ} 10$. Rio de Janeiro: FIBGE. 1992a. Censo Demográfico 1991. Resultados Preliminares. Rio de Janeiro: FIBGE. 1992b. A nuário Estatístico do Brasil, 1992. Rio de Janeiro: Secretaria de Planejamento, Orçamento e Coordenação, FIBGE.

HAIRSTON, N. G. \& MEILLON, B., 1968. On the inefficiency of transmission of Wuchereria bancrofti from mosquito to human host. Bulletin of the W orld Health Organization, 38: 135-141.

MELO, M. L., 1978. M etropolização e Subdesenvolvimento - 0 caso do Recife. Recife: Editora da Universidade Federal de Pernambuco.

MELO, N. M. L., 1990. Estado, Capital Financeiro, Espaço Habitacional - $\mathrm{O}$ caso da Região $\mathrm{Me}$ tropolitana do Recife. Recife: Editora da Universidade Federal de Pernambuco.
MELO, V. L. M. O., 1991. O PROM ORAR como Instrumento de Intervenção do Estado. Tese de Mestrado, Recife: Universidade Federal de Pernambuco.

MS (Ministério da Saúde), 1983. Controle das Endemias em 1983. Brasília: Superintendência de Campanhas de Saúde Pública, MS. (Mimeo.) , 1985. O controle das Endemias no Brasil (de 1979 a 1984). Brasília: Superintendência de Campanhas de Saúde Pública, MS. (Mimeo.)

, 1989. Programa de Controle da Filariose. Relatório Anual. Recife: Superintendência de Campanhas de Saúde Pública, Diretoria Regional de Pernambuco, MS. (Mimeo.) , 1990. Programa de Controle da Filariose. Relatório Anual. Recife: Superintendência de Campanhas de Saúde Pública, Diretoria Regional de Pernambuco, MS. (Mimeo.)

MOTT, K. E.; DESJEUX, P.; MONGAUO, A.; RANQUE, P. \& RADT, P., 1990. Parasitic diseases and development. Bulletin of the World Health Organization, 68: 691-698.

MOURA, A. S., 1990. Terra do M angue: Invasões Urbanas no Recife. Recife: Editora Massangana.

MORAIS, H. M., 1982. A Filariose no Recife: Um estudo epidemiológico. Tese de Mestrado, São Paulo: Universidade de São Paulo.

NELSON, G. S., 1979. Current concepts in parasitology. Filariasis. New England Journal of Medicine, 300: 136-139.

OMS (Organización Mundial de la Salud), 1988. Lucha contra la filaríasis linfática - M anual para personal sanitario. Genebra: Organización Mundial de la Salud.

PCR (Prefeitura da Cidade do Recife), 1991. Plano Diretor de Desenvolvimento da Cidade do Recife - Uso e ocupações do solo. Versão Preliminar. Recife: Secretaria de Planejamento Urbano/ PROCENGE/URBANA/ACQUAPLAN.

RACHOU, R. G., 1957. Distribuição geográfica das filarioses humanas no Brasil. Revista Brasileira de M alariologia e Doenças Tropicais, 9: 79-100.

RACHOU, R. G.; VILELA, A. M.; CRUZ, A. E. \& CARVALHO, G., 1956. A filariose bancroftiana em Recife (Pernambuco): Resultado de um inquérito realizado em 1954-1955. Revista B rasileira de Malariologia e Doenças Tropicais, 8: 359-367.

ROCHA, S. \& VILLELA, R., 1990. Caracterização da subpopulação pobre metropolitana nos anos 80 - Resultados de uma análise multivariada. Revista Brasileira de Economia, 44: 35-52. 
SABROZA, P. C., 1991. Espaço e produção de endemias. In: A nales del II Taller de la Asociación Latino-A mericana de Medicina Social, pp. 237-247, Caracas: Rectorado de la Universidad Central de Venezuela.

SABROZA, P. C., TOLEDO, L. M. \& OSANAI, C. H., 1992. A organização do espaço e os processos endêmicos-epidêmicos. In: Saúde, A mbiente e Desenvolvimento (M. C. Leal, P. C. Sabroza, R. H. Rodríguez \& P. M. Buss, orgs.), vol. II, pp. 57-77, São Paulo: Hucitec/Rio de Janeiro: Abrasco.
SANTOS, M., 1979. O Espaço Dividido: Os Dois Circuitos da Economia Urbana dos Países Subdesenvolvidos. Rio de Janeiro: Livraria Francisco Alves Editora.

SILVA, L. J., 1985. Crescimento urbano e doença: a esquistossomose no município de São Paulo. Revista de Saúde Pública, 19: 1-7.

WHO (World Health Organization), 1992. Fifth Report of the WHO Expert Committee on Filariasis, 1992. Lymphatic filariasis: The disease and its control. Geneva: WHO. 